\title{
Philosophiques
}

\section{Mot de la rédaction}

Volume 31, numéro 2, automne 2004

URI : https://id.erudit.org/iderudit/009808ar

DOI : https://doi.org/10.7202/009808ar

Aller au sommaire du numéro

Éditeur(s)

Société de philosophie du Québec

ISSN

0316-2923 (imprimé)

1492-1391 (numérique)

Découvrir la revue

Citer ce document

(2004). Mot de la rédaction. Philosophiques, 31(2), 293-293.

https://doi.org/10.7202/009808ar

Ce document est protégé par la loi sur le droit d'auteur. L'utilisation des services d'Érudit (y compris la reproduction) est assujettie à sa politique d'utilisation que vous pouvez consulter en ligne.

https://apropos.erudit.org/fr/usagers/politique-dutilisation/
Cet article est diffusé et préservé par Érudit.

Érudit est un consortium interuniversitaire sans but lucratif composé de l’Université de Montréal, l'Université Laval et l'Université du Québec à Montréal. Il a pour mission la promotion et la valorisation de la recherche. https://www.erudit.org/fr/ 


\section{Mot de la rédaction}

Philosophiques célèbre cette année son trentième anniversaire. Pour souligner cet événement, nous publions dans ce volume un index répertoriant tous les titres parus depuis le premier numéro en 1974. Plus qu'un simple outil de travail, cet index témoigne aussi bien de la qualité et de la diversité des textes qui ont contribué au développement de la revue depuis sa fondation que des changements qui en ont marqué l'évolution. Fidèle à sa vocation initiale et dans un esprit d'ouverture face à l'évolution de la philosophie d'ici et d'ailleurs durant cette période, l'organe officiel de la Société de philosophie du Québec a dû en effet s'adapter et prendre les moyens pour favoriser son épanouissement. Parmi les mesures concrètes qui ont été mises en place depuis le début des années 1990, mentionnons la formation d'un comité scientifique international, la collaboration scientifique accrue des chercheurs étrangers et la publication, depuis 1999, d'une version numérique de la revue. Tous les abonnés à la revue et tous les membres en règle de la SPQ peuvent désormais consulter, sans frais additionnels, la version numérique de Philosophiques (à partir du volume 26) en enregistrant leur adresse électronique à l'adresse suivante : http://www.erudit.org/abonnement/. La numérisation des volumes 1 à 25 , que nous souhaitons entreprendre prochainement, est une autre mesure concrète visant à poursuivre le travail entrepris au cours des dernières années. À cela s'ajoutent la nouvelle rubrique Disputatio, qui rend possible une discussion plus large et plus diversifiée d'un ouvrage que ne le permettent les autres rubriques, et la publication en alternance, depuis la fin des années 1990, d'un numéro conventionnel et d'un numéro thématique dont la responsabilité est confiée à un chercheur reconnu dans son champ de spécialisation. Le nouveau comité de rédaction, en poste depuis janvier 2004, tâchera de consolider ces acquis et de veiller à la qualité scientifique de Philosophiques et à son rayonnement international. 